\title{
Sistem Informasi Analisa dan Pengembangan Persediaan Barang pada Mini Market
}

\author{
${ }^{1}$ Rometdo Muzawi, ${ }^{2}$ Yoyon Efendi \\ ${ }^{1,2}$ STMIK Amik Riau \\ rometdomuzawi@stmik-amik-riau.ac.id ${ }^{1)}$ yoyonefendi@stmik-amik-riau.ac.id ${ }^{2}$ )
}

\begin{abstract}
ABSTRAK. Sistem persediaan (Inventory) pada Mini Market Rina Bukittinggi. Penyajian laporan-laporan informasi persediaan barang disajikan dalam bentuk tabel akan lebih jelas dan akurat bila dibandingkan dengan laporan yang sebelumnya hanya dibuat dengan cara manual yang mempunyai tingkat kesalahan yang tinggi. agar dapat sekiranya mempermudah dalam penyediaan informasi yang berhubungan dengan data-data persediaan barang-barang. perancangan aplikasinya, digunakan bahasa pemrograman visual basic 6.0 yang bertujuan agar lebih mudah dimengerti oleh pemakai (User).
\end{abstract}

Kata Kunci: Sistem Informasi, Persediaan Barang, Mini Market

ABSTRACT. Inventory information system Mini Market Rina Bukittinggi. The abstract Presentation of report related to sale information presented in the form of tables which this matter assumed will be more clear and accurate when compared to previous report only made by using manually system which have high probability mistakes. Biggest benefit this presentation report is can be make it easier to preparing inventory information. And in application design, using Visual Basic 6.0 programming with aim to be easier understood by user.

Keywords: Information Systems, Inventory, Mini Market.

\section{PENDAHULUAN}

Dalam dunia perdagangan seperti saat ini dengan iklim persaingan yang semakin ketat, penyajian informasi yang akurat, cepat dan tepat adalah modal utama dalam menghadapi persaingan.

Perkembangan ilmu pengetahuan dan tekhnologi telah memperlihatkan kemajuan yang sangat pesat untuk dapat diaplikasikan disemua bidang. Salah satu contoh kemajuan itu adalah dengan terciptanya komputer, dimana komputer mempunyai banyak kegunaan dan kepraktisan kerja yang sangat tinggi untuk mengolah data yang rumit dan dalam jumlah yang banyak.

Pada perusahaan yang ingin bersaing dan mengejar keuntungan yang besar, maka komputer merupakan alat bantu yang sangat bermanfaat dalam proses kegiatan perusahaan, termasuk proses penyediaan informasi. Informasi merupakan sumber data yang diperlukan oleh berbagai pihak di perusahaan, baik pihak intern maupun pihak ekstern perusahaan, salah satu informasi yang sangat penting adalah sistem informasi persediaan (Inventory).

Sistem inventory (persediaan) pada Mini Market Rina Bukittinggi masih dilaksanakan secara manual sehingga menyulitkan untuk mengetahui persediaan barang yang ada. Informasi mengenai sistem persediaan ini sangat penting karena proses pembelian maupun penjualan berawal dari sistem ini, untuk itulah sangat diperlukan informasi yang akurat mengenai sistem persediaan ini.

\section{ANALISA MASALAH DAN HASIL}

\subsection{Analisa Masalah}

Analisa masalah yang sedang berjalan dilakukan guna untuk mengetahui permasalahan yang sebenarnya dihadapi oleh Mini Market Rina Bukittinggi. Penganalisaan ini berguna untuk memberikan bentuk-bentuk alternatif yang dibutuhkan. Diharapkan dengan adanya bentuk-bentuk alternatif ini, akan memberikan bentuk laporan yang lebih baik serta mudah untuk lebih dipahami oleh pemakai sistem ataupun pihak yang berkepentingan dengan kinerja sistem ini. Adapun masalah-masalah yang ditemukan dari sistem yang sedang berjalan di Mini Market Rina Bukittinggi adalah :

1. Masih belum jelasnya program perhitungan persediaan barang.

Pada saat ini masih belum ada program perhitungan yang jelas di Mini Market Rina Bukittinggi, jumlah keluar masuknya barang tidak begitu pasti, sehingga untuk mengetahui keadaan persediaan barang sangat sulit dan sering terjadi kesalahan-kesalahan, masalah ini dapat menimbulkan kerugian dan tahap yang lebih fatalnya bisa terjadi kebangkrutan.

2. Penggunaan cara manual dalam sistem pencatatan persediaan. 
Dalam pencatatan proses operasionalnya, yaitu proses pembelian, proses penjualan dan proses pencataan persediaan barang masih menggunakan kalkulator sebagai alat bantu untuk perhitungan dan dicatat dalam sebuah buku atau kertas-kertas yang penyimpanannya tidak begitu baik sehingga sering terjadi kehilangan arsip-arsip yang diperlukan dan untuk mencari kembali sangatlah sulit.

3. Laporan yang dihasilkan tidak akurat.

Disebabkan karena proses perhitungan yang masih belum jelas dan pencataan manajemen persediaan barang masih dengan cara yang manual, maka laporan-laporan yang dihasilkan sangat tidak akurat dan pembuatannya memakan waktu yang relatif lama, sehingga pihak manajer sangat sulit untuk mengambil keputusan-keputusan yang tepat. Ketidak akuratan dalam mengambil keputusan akan membuat kinerja perusahaan tidak efisien dan tidak efektif.

\subsection{Hasil}

\subsubsection{Hasil Analisa dan Pengembangan Input}

Dalam melakukan suatu proses pengolahan data, sekiranya diperlukan suatu analisa input dimana bertujuan untuk mengetahui data-data apa saja yang dibutuhkan untuk pemrosesan nantinya oleh sistem. Pada Mini Market Rina Bukittinggi data input yang digunakan sebagai bahan masukan adalah Faktur Pembelian Barang (FPB) dari Supplier yang disesuaikan dengan Daftar Pembelian Barang (DPB) dari pemilik toko, daftar permintaan dari konsumen yang ditunjukkan pada Gambar 1 dan 2. Semua elemen-elemen input ini merupakan awal dari proses pengolahan data persediaan.

MINI MARKET RINA BUKITTINGGGI

Jin. Syech Ibrahim Musa No.64-F Tengah Sawah - Bukittinggi Telp. (0752) 34367

DAFTAR PEMBELIAN BARANG

\begin{tabular}{|c|c|c|c|}
\hline No & Nama Barang & Satuan & Jumlah \\
\hline 99 & $\times(50)$ & $\times(15)$ & 9999 \\
\hline$/ 2$ & & & \\
\hline & & & \\
\hline
\end{tabular}

BUKITTINGGI, dd / mm /yYYY MANAJER

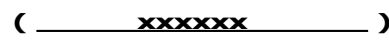

Gambar 1. Bentuk Daftar Pembelian Barang. Sumber : Mini Market Rina Bukittinggi

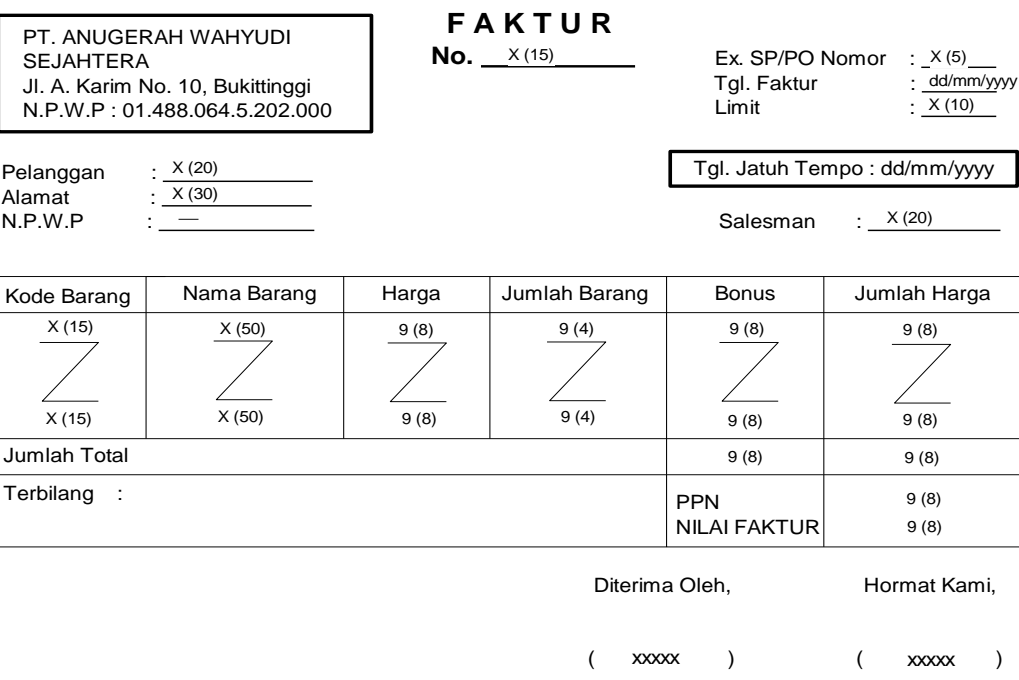

Gambar 2. Bentuk Faktur Pembelian Barang. Sumber : Mini Market Rina Bukittinggi 


\subsubsection{Hasil Analisa dan Pengembangan Proses}

Setelah melakukan penganalisaan terhadap input (masukan) yang diperoleh dari Faktur Pembelian Barang (FPB) dari Supplier yang disesuaikan dengan Daftar Pembelian Barang (DPB) dari pemilik toko serta Daftar Permintaan dari konsumen sebagai bahan masukan awal, maka selanjutnya dilakukan proses pengolahan data penjualan berdasarkan input tersebut, Adapun proses yang dilakukan adalah sebagai berikut

1. Faktur Pembelian Barang (FPB) yang telah dicek oleh Bagian persediaan diserahkan ke Kasir untuk dilakukan pencatatan transaksi pembelian dan membuat laporan pembelian barang.

2. Bagian persediaan Menyerahkan barang sesuai dengan keinginan Konsumen dan barang tersebut dibawa ke Kasir untuk pencatatan transaksi penjualan yang menghasilkan laporan penjualan dan bon pembayaran. Laporan penjualan akan diberikan ke Manajer dan bon pembayaran diberikan ke Konsumen beserta barang yang diinginkan oleh Konsumen.

\subsubsection{Hasil Analisa dan Pengembangan Output}

Berdasarkan hasil dari analisa input dan proses yang sedang berjalan pada saat ini, maka selanjutnya perlu sekiranya dilakukan analisa terhadap output yang ada yaitu berupa laporan-laporan yang berhubungan dengan persediaan barang. Laporan-laporan tersebut dibuat oleh Kasir. Dalam pembuatan laporan tersebut dilakukan dengan menggunakan metode manual dimana laporan diisi langsung oleh Kasir. Laporan tersebut selanjutnya diserahkan kepada Manajer sebagai bahan pertimbangan untuk mengambil suatu keputusan. Bentuk laporannya bisa dilihat pada Gambar 3.

MINI MARKET RINA BUKITTINGGI

\section{Jin. Syech Ibrahim Musa No.64-F Tengah Sawah - Bukittinggi \\ Telp. (0752) 34367}

LAPORAN SALDO STOCK

s/d dd/mm/yyyy

\begin{tabular}{|c|c|c|c|c|c|c|c|}
\hline No & Kode Barang & Nama Barang & Jumlah masuk & Jumlah keluar & Saldo Stock & Harga Beli & Jumlah \\
\hline 99 & $X(15)$ & $X(50)$ & $9(4)$ & $9(4)$ & $9(4)$ & $9(8)$ & $9(8)$ \\
\hline 99 & $X(15)$ & $X(30)$ & $9(4)$ & $9(4)$ & $9(4)$ & $9(8)$ & $9(8)$ \\
\hline & & & & & & Total & $9(8)$ \\
\hline
\end{tabular}

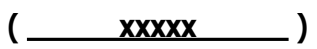

Gambar 3. Bentuk Laporan Persediaan Barang.

\subsubsection{Menu Utama}

Menu utama ini menggambarkan aliran program untuk menu utama pada komputerisasi sistem informasi penjualan. Flowchart bisa dilihat pada Gambar 4. 


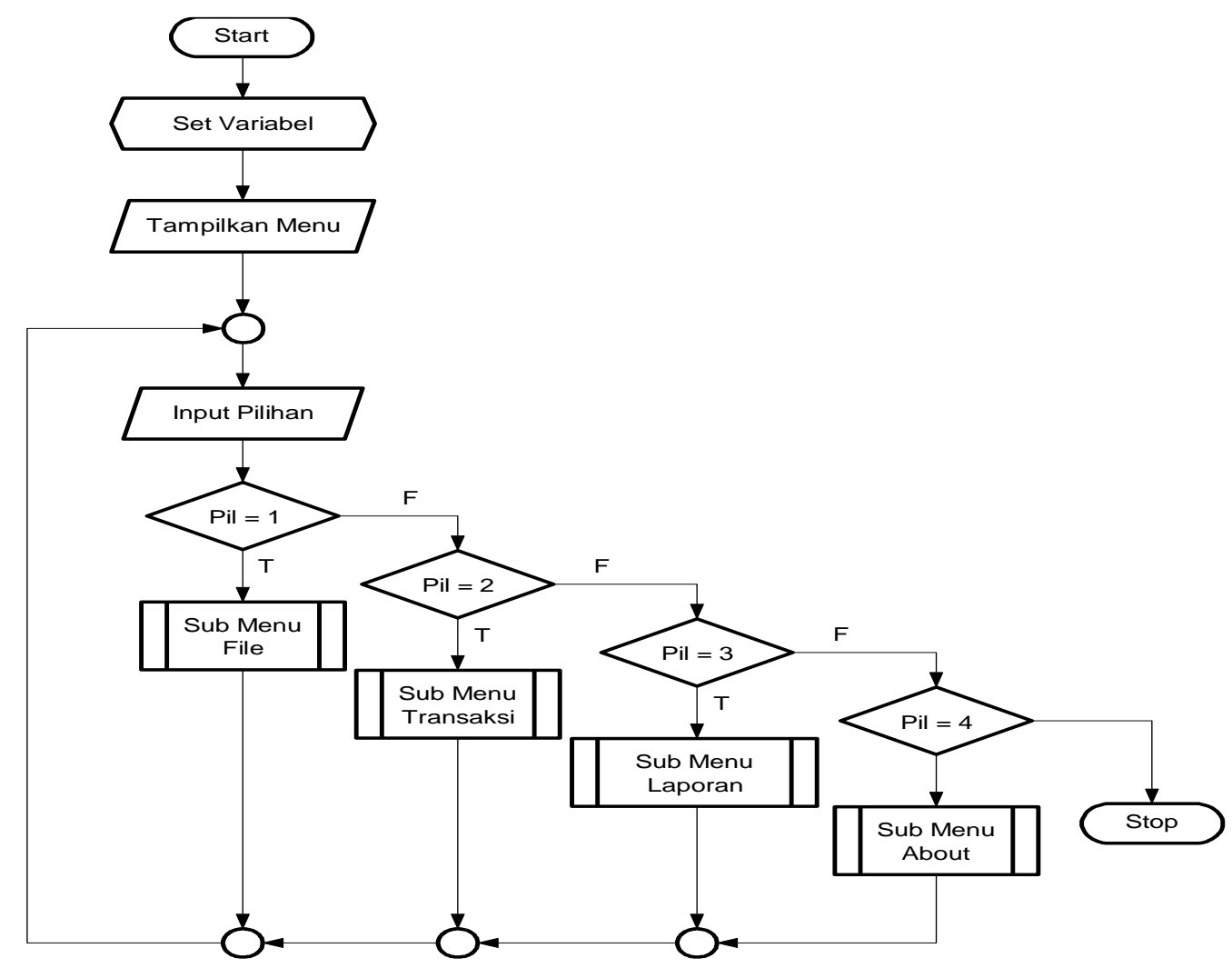

Gambar 4. Flowchart Menu Utama

Pada menu file terdapat beberapa sub menu lagi yang terdiri dari file Supplier dan file Data Barang.

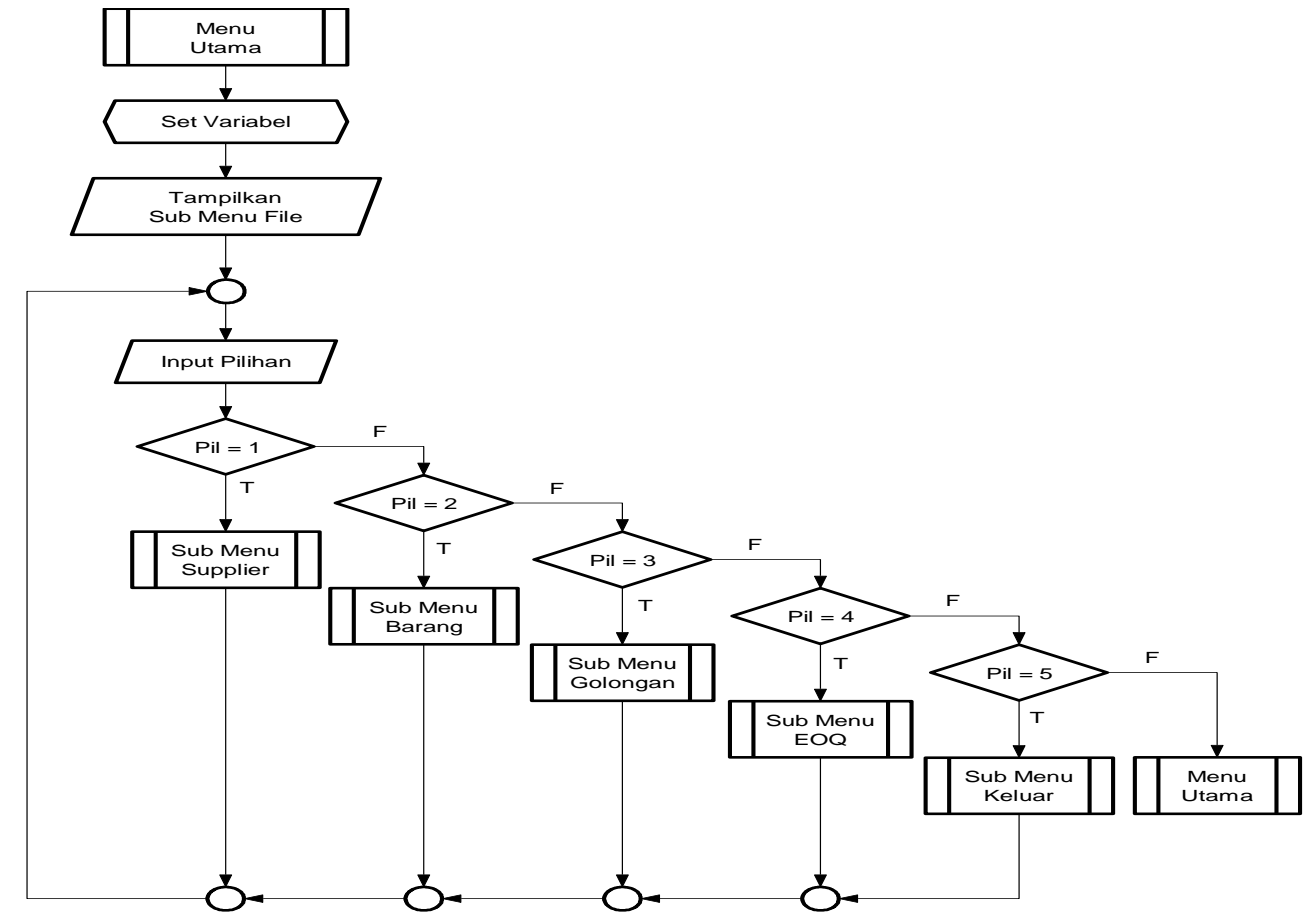

Gambar 5. Flowchart Menu File 
Pada menu transaksi terdapat beberapa sub menu lagi yang terdiri dari transaksi pembelian dan transaksi penjualan barang

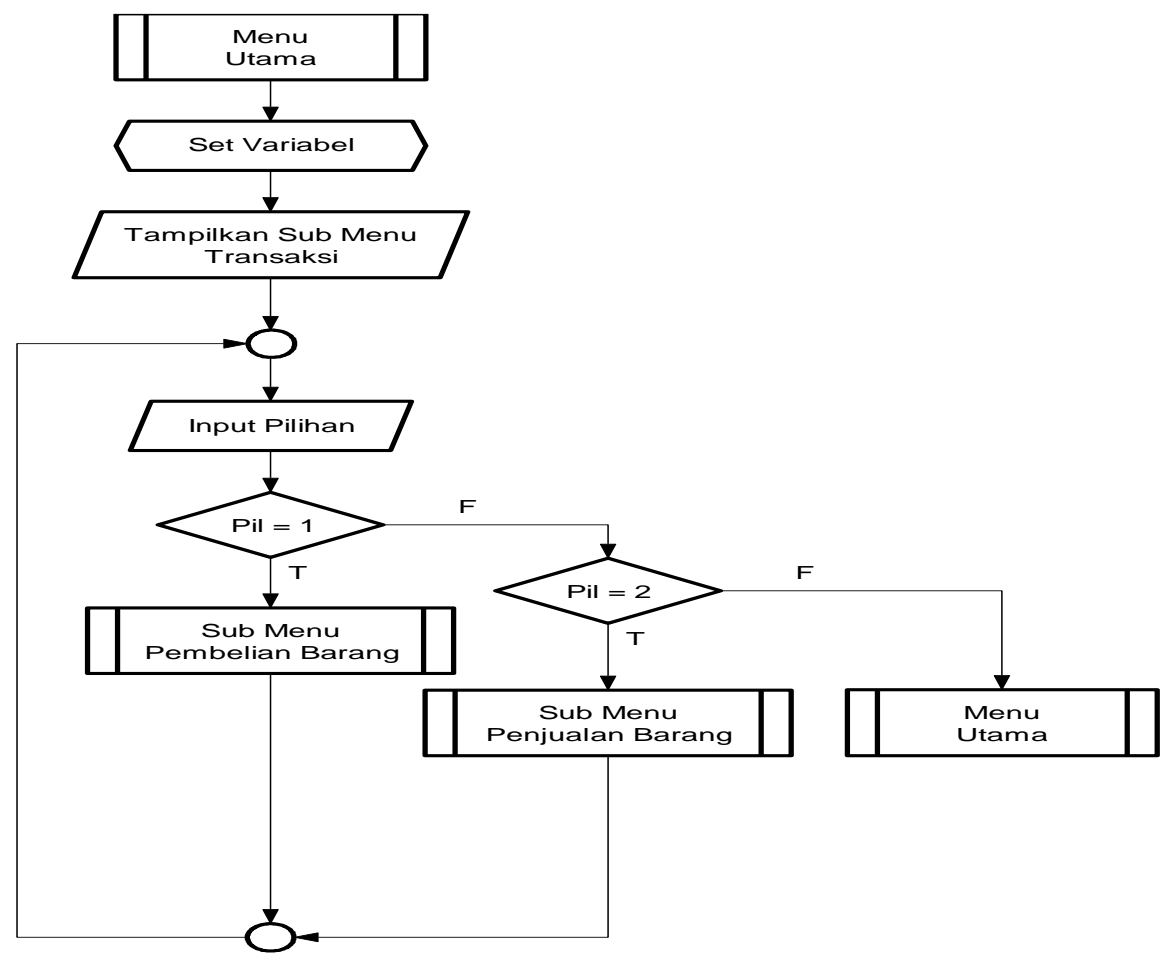

Gambar 6. Flowchart Menu Transaksi

Pada menu laporan transaksi terdapat beberapa sub menu lagi yang terdiri dari laporan pembelian barang laporan serta penjualan barang.

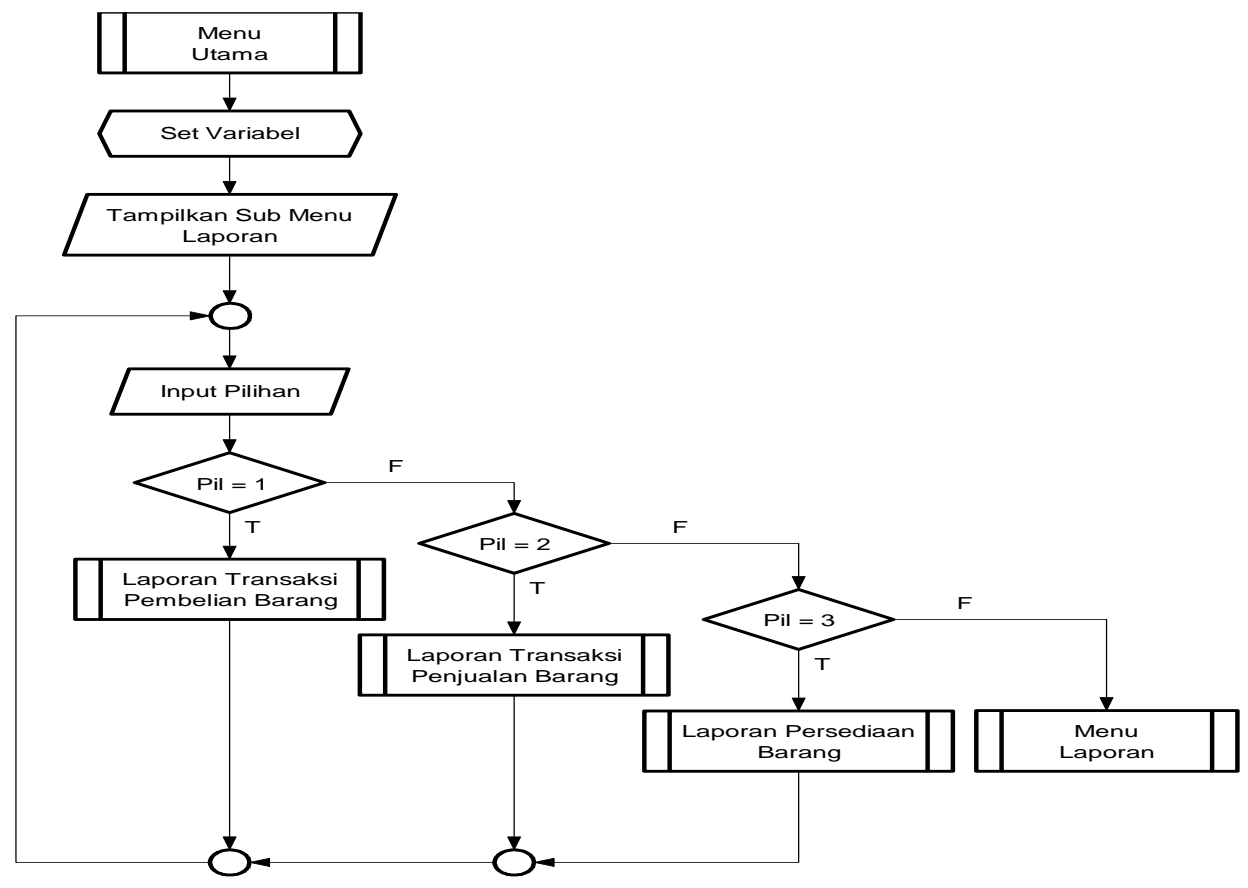

Gambar 7. Flowchart Menu Laporan 
Proses pengentrian data Supplier yang baru saja terlibat dalam transaksi pembelian barang

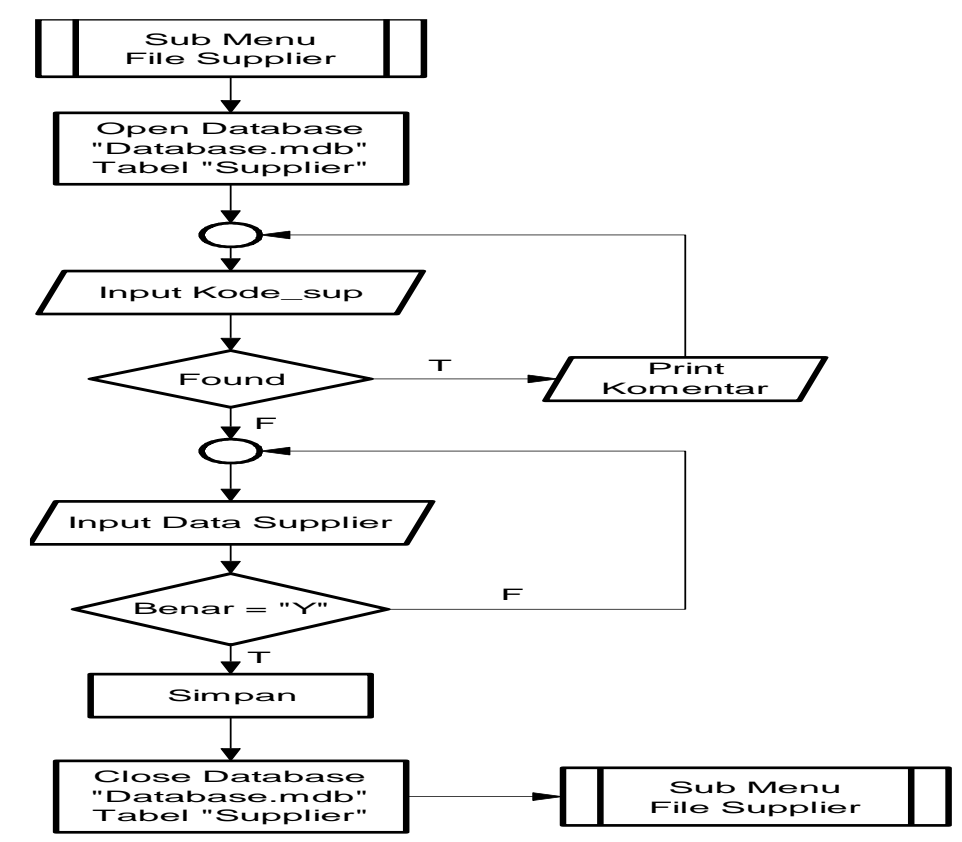

Gambar 8. Flowchart Sub Menu File Entry Supplier

Menggambarkan proses pengentrian data barang yang baru saja terlibat dalam transaksi pembelian barang.

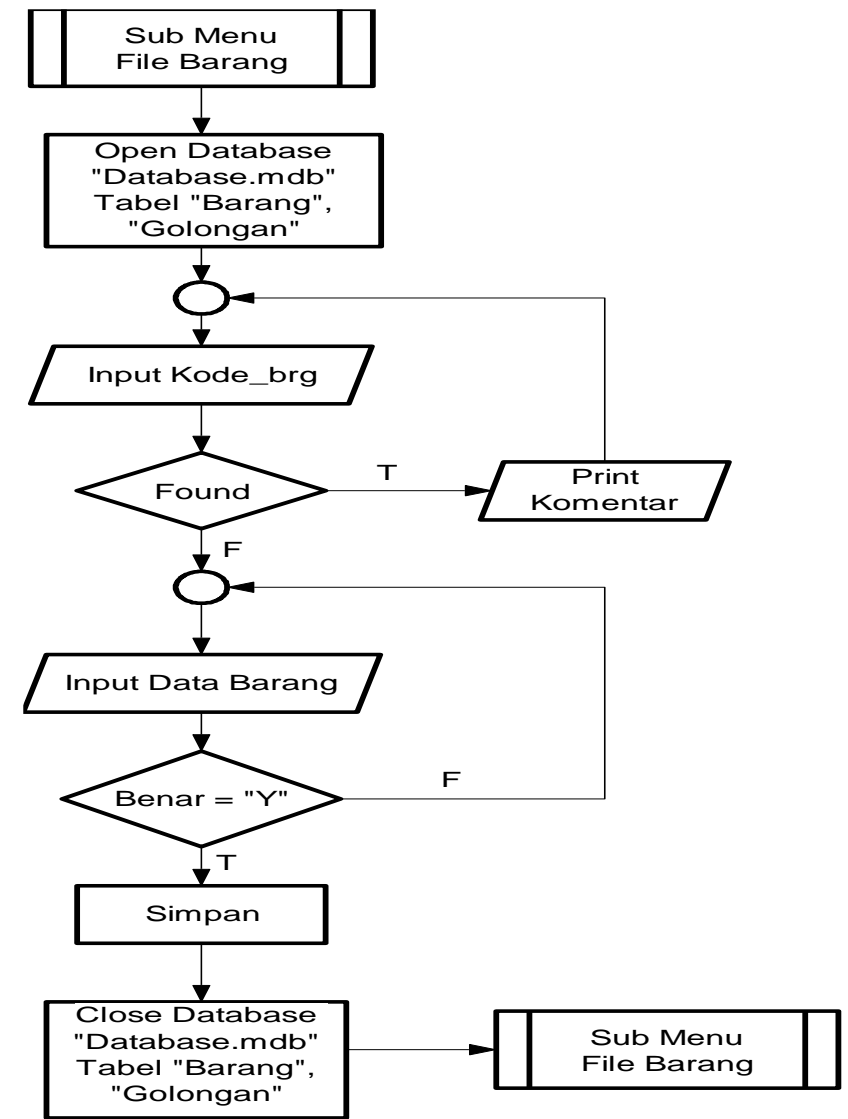

Gambar 9. Flowchart Sub Menu File Entry Barang 
Menggambarkan proses pengentrian golongan barang yang nantinya akan menentukan jenis barang berdasarkan golongan yaitu pada dua digit pertama di kode barang.

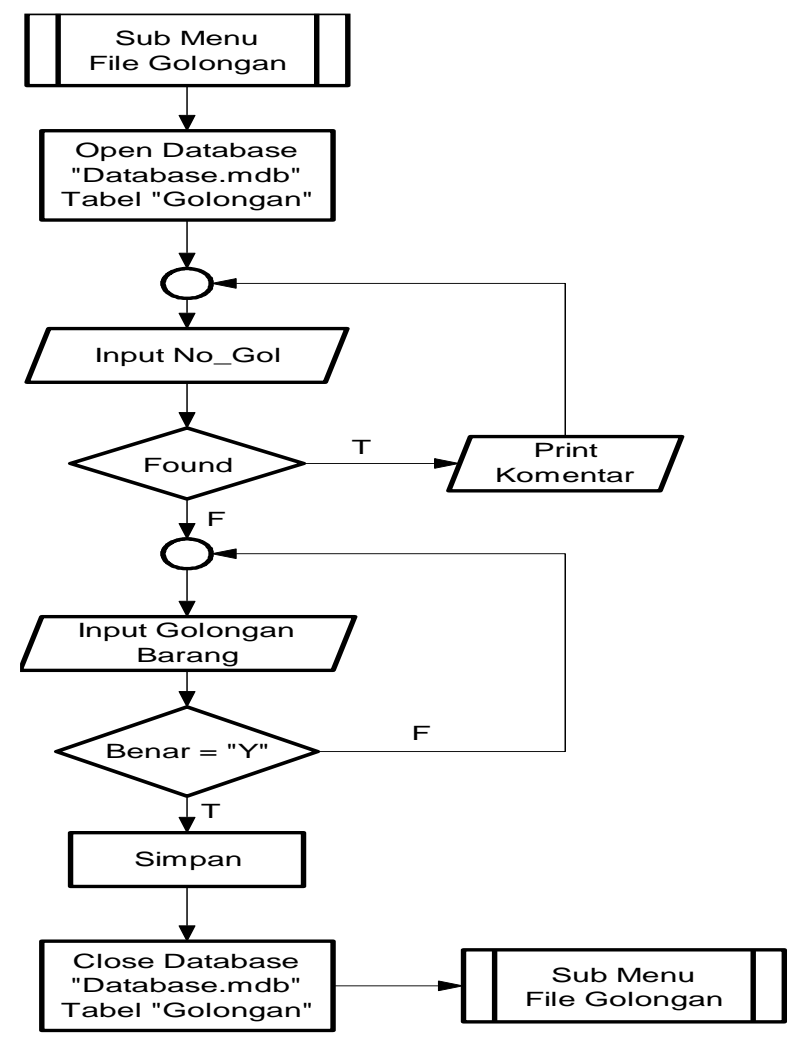

Gambar 10. Flowchart Sub Menu File Entry Golongan Barang

Menggambarkan proses untuk menampilkan informasi terhadap data-data pembelian (order) barang yang telah dilaksanakan. Laporan ini dalam format keseluruhan dan perfaktur.

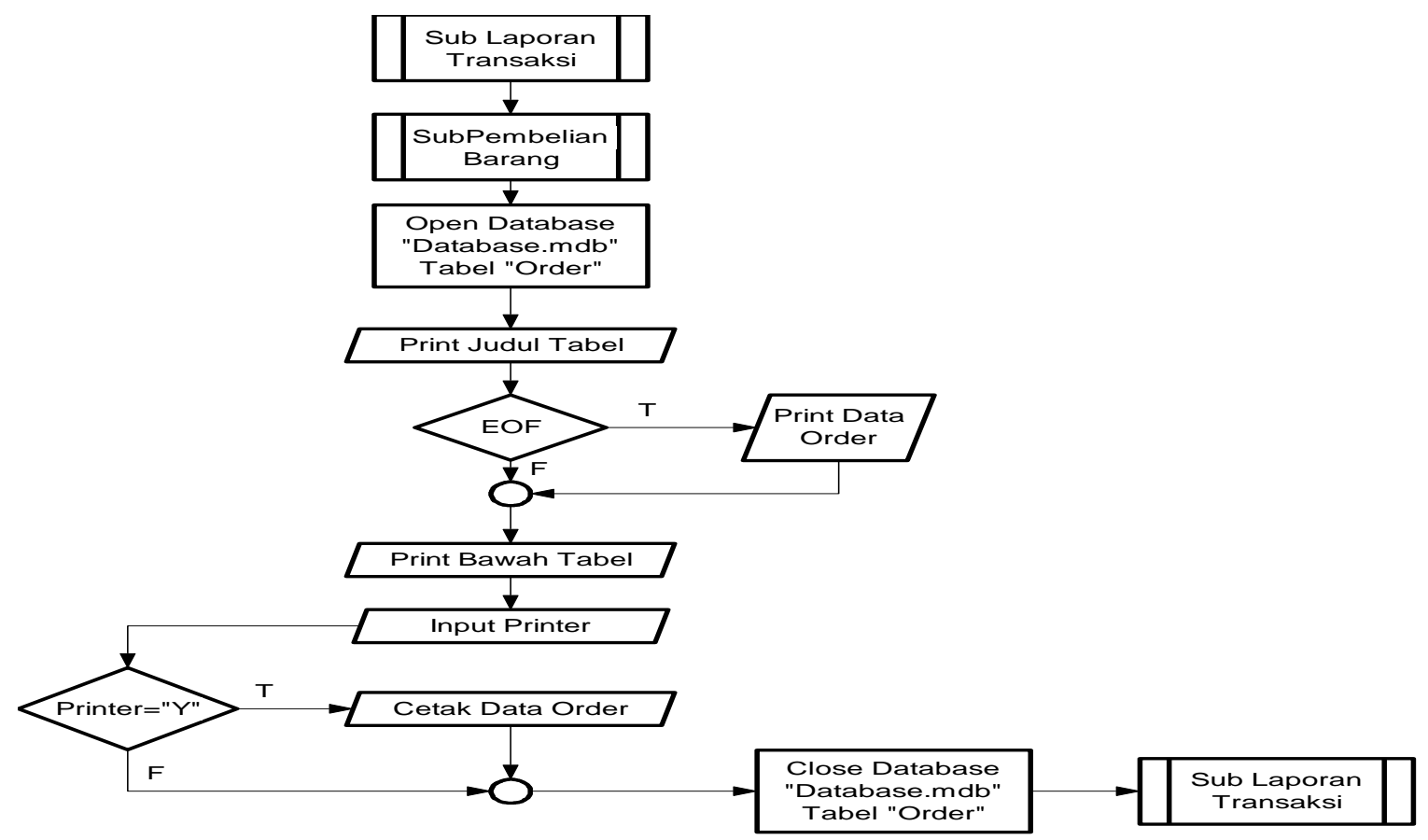

Gambar 11. Flowchart Sub Menu Laporan Transaksi Pembelian (Order) Barang 
Menggambarkan proses untuk menampilkan informasi terhadap data-data penjualan obat yang telah dilaksanakan. Laporan ini dalam format keseluruhan dan per faktur.

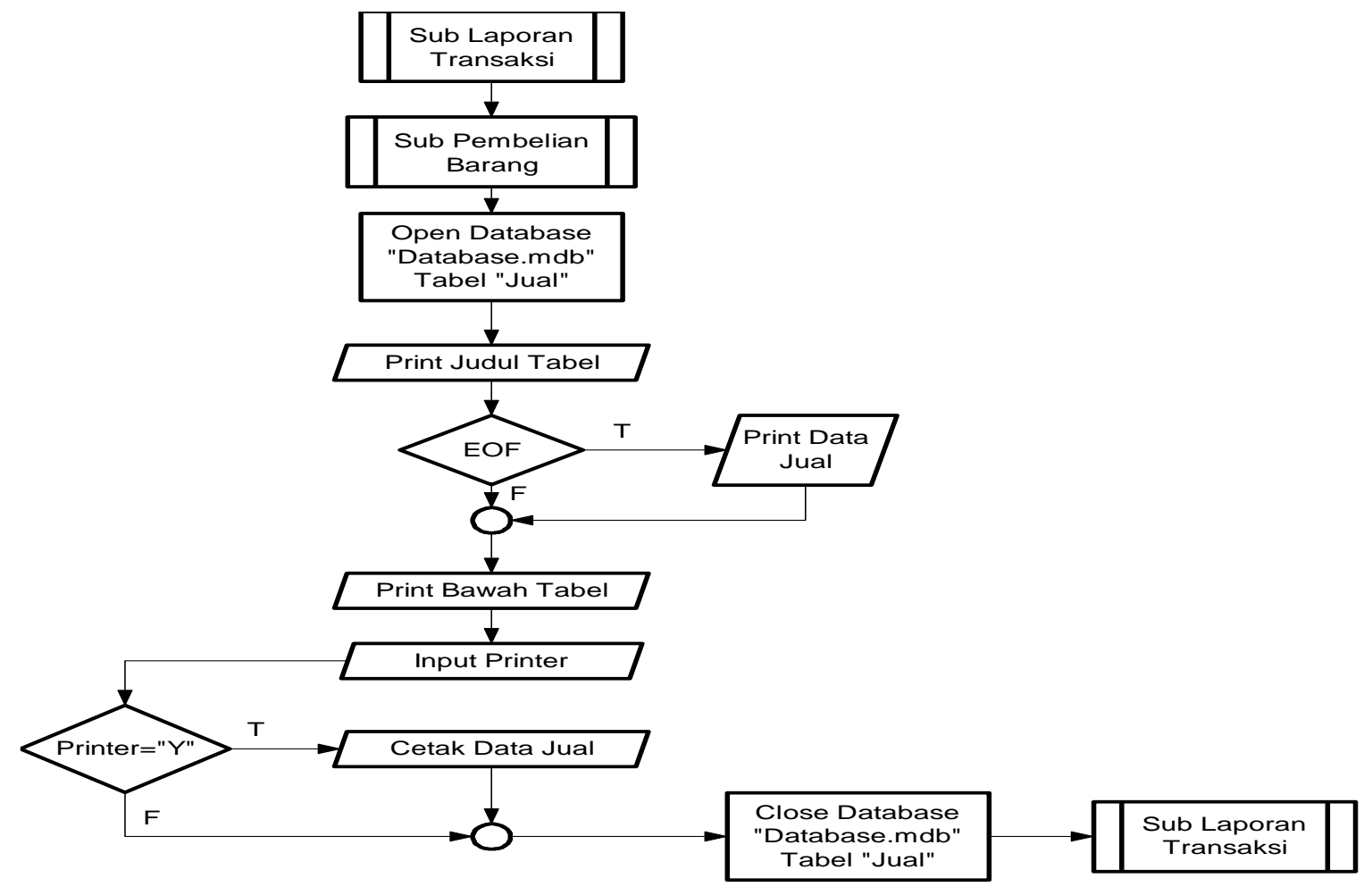

Gambar 12. Flowchart Sub Menu Laporan Transaksi Penjualan Barang

Menggambarkan proses untuk menampilkan informasi terhadap data-data persediaan barang yang masih ada, dimana laporan ini berguna untuk mengawasi ketersediaannya barang untuk para konsumen.

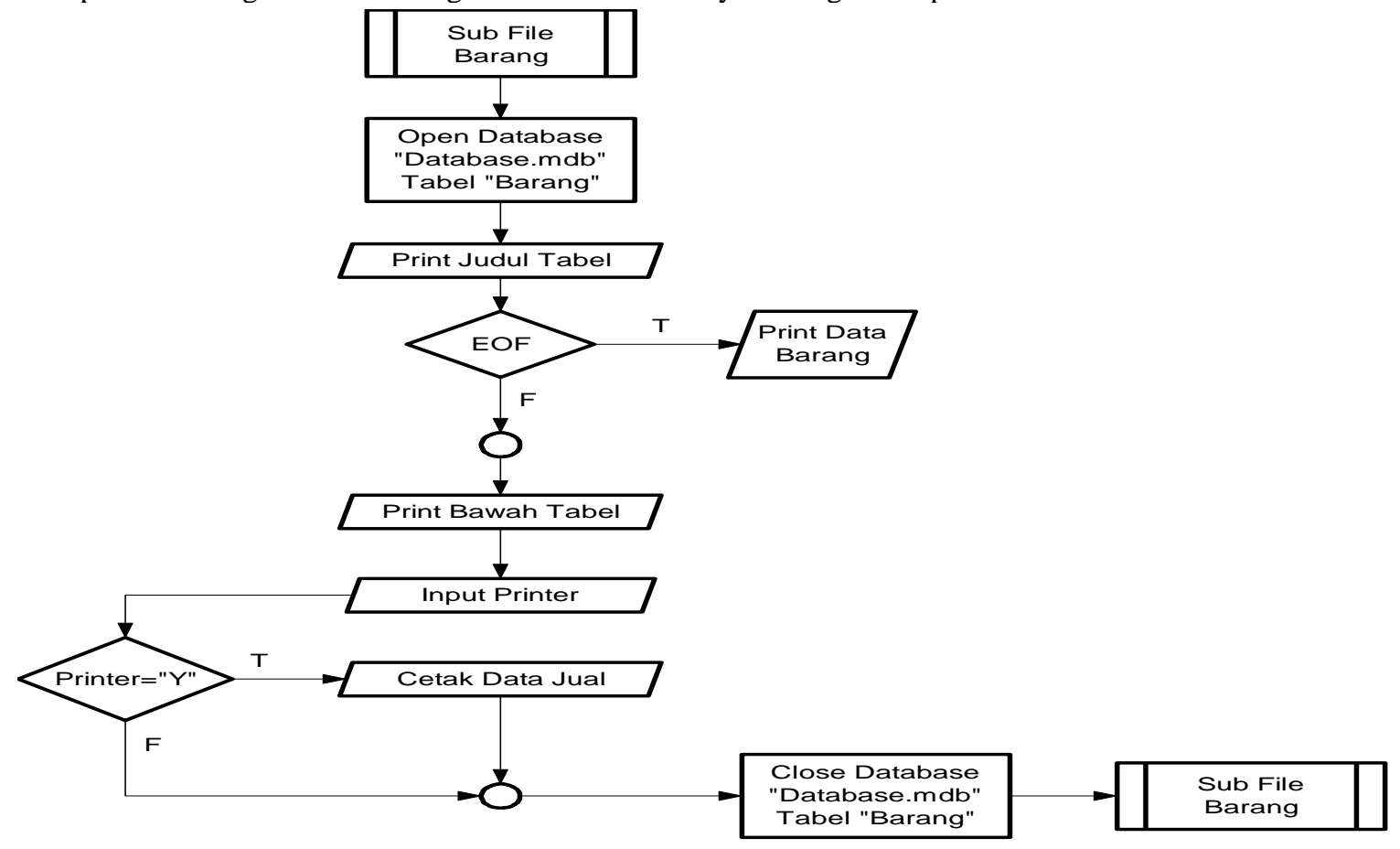

Gambar 13. Flowchart Sub Menu Laporan Persediaan Barang 


\section{PENGUJIAN}

3.1 Tampilan

Pada pengujian dapat dilihat dari menu utama sebagai berikut:

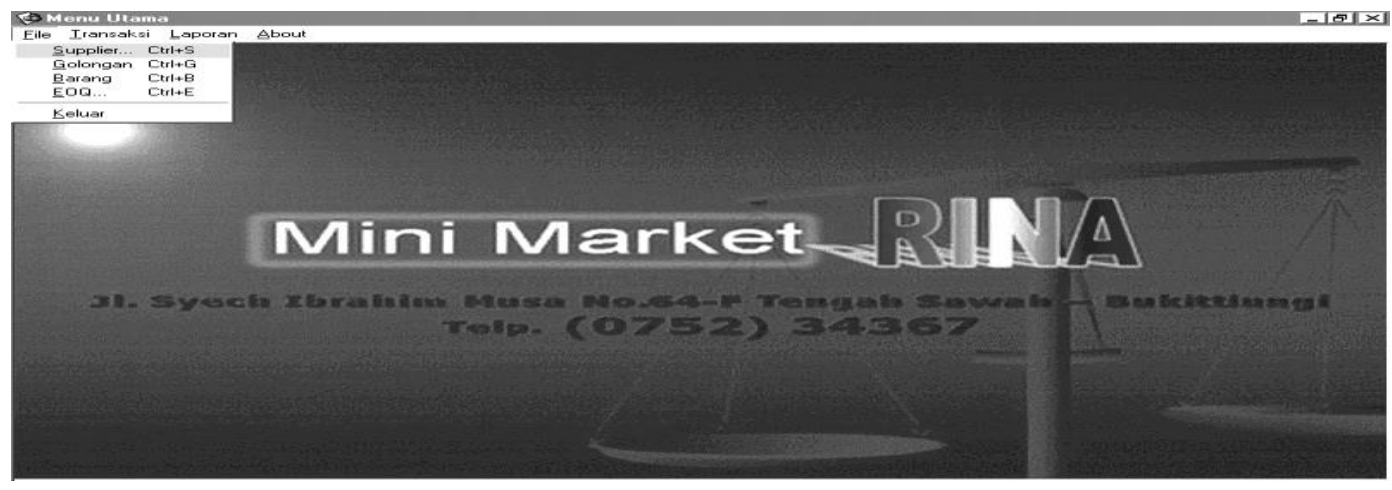

Gambar 14. Tampilan Menu Utama

Tampilan Entry Data Suplier dapat dilihat pada gambar 15.

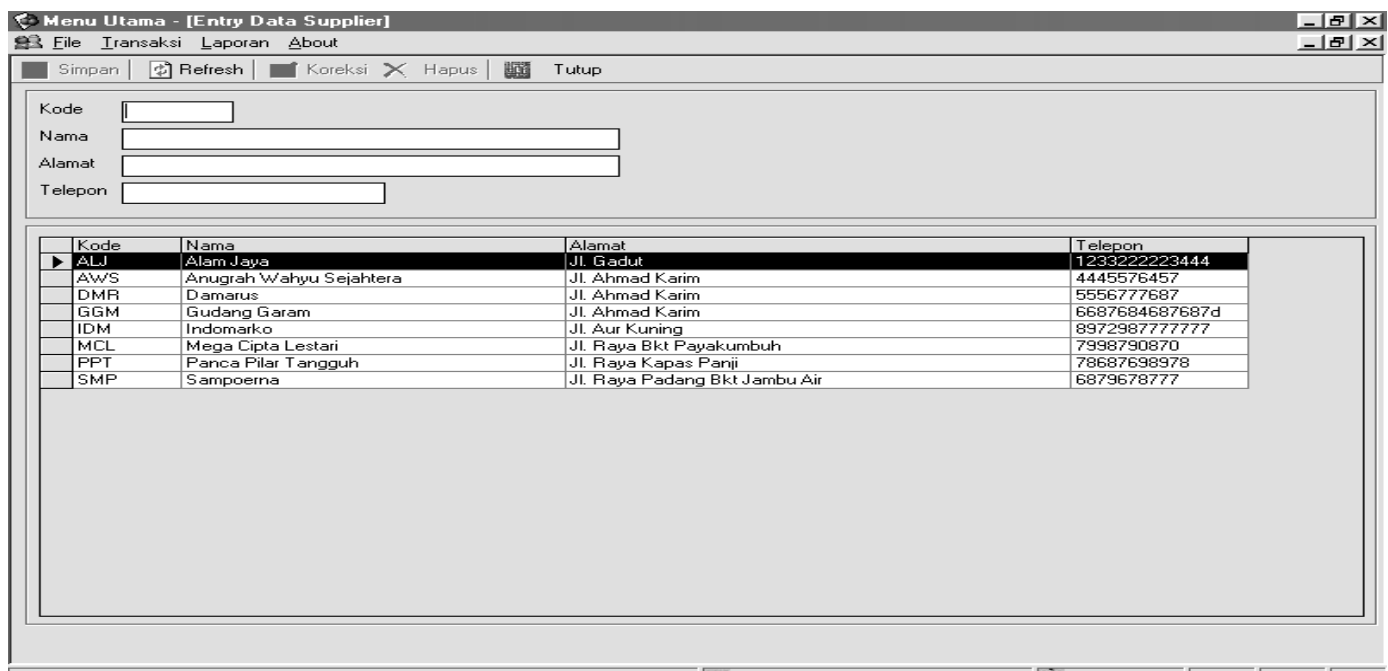

Gambar 15. Tampilan Entry Data Suplier

Tampilan Entry Data golongan dapat dilihat pada gambar 16.

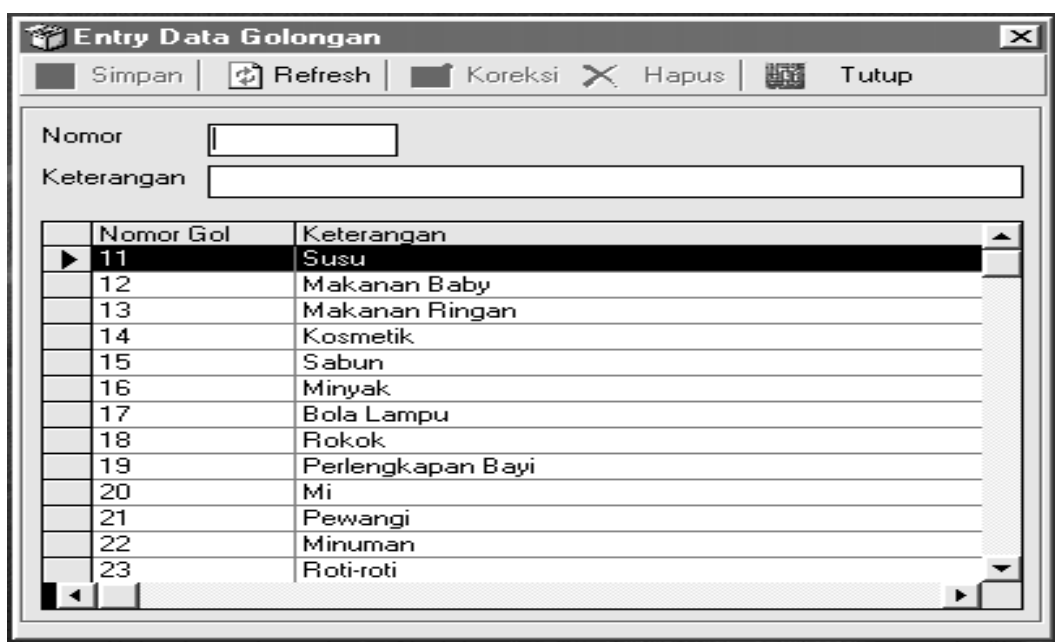

Gambar 16. Tampilan Entry Data Golongan 
Tampilan Entry Data Barang dapat dilihat pada gambar 17 berikut:

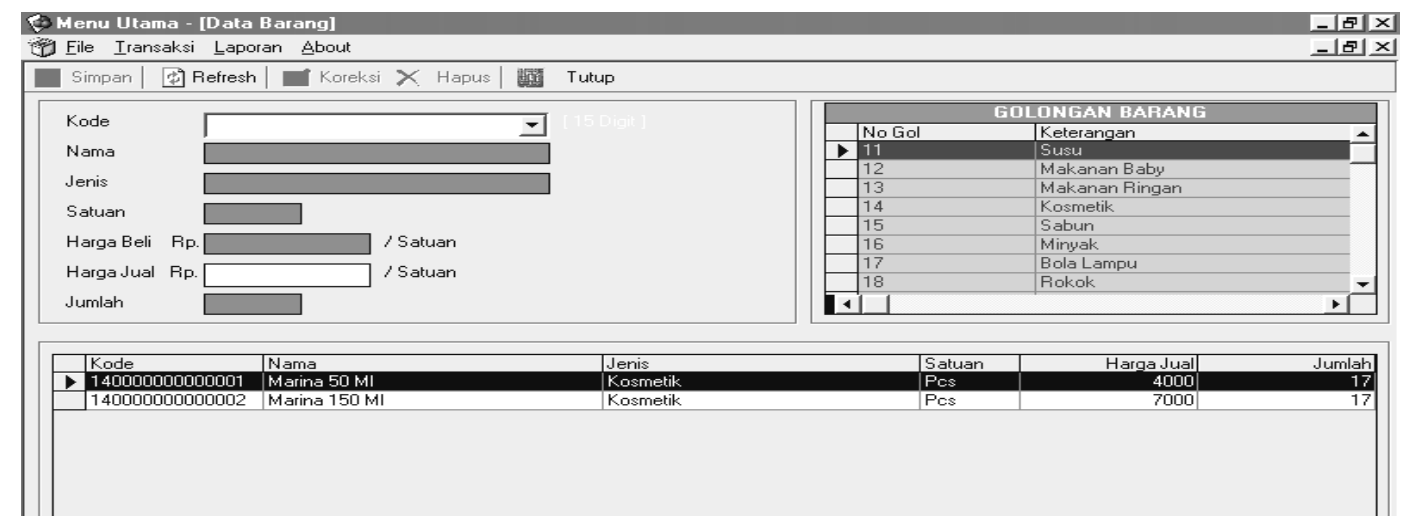

Gambar 17. Tampilan Entry Data Barang

Tampilan Entry Data Transaksi Pembelian dapat dilihat pada gambar 18 berikut:

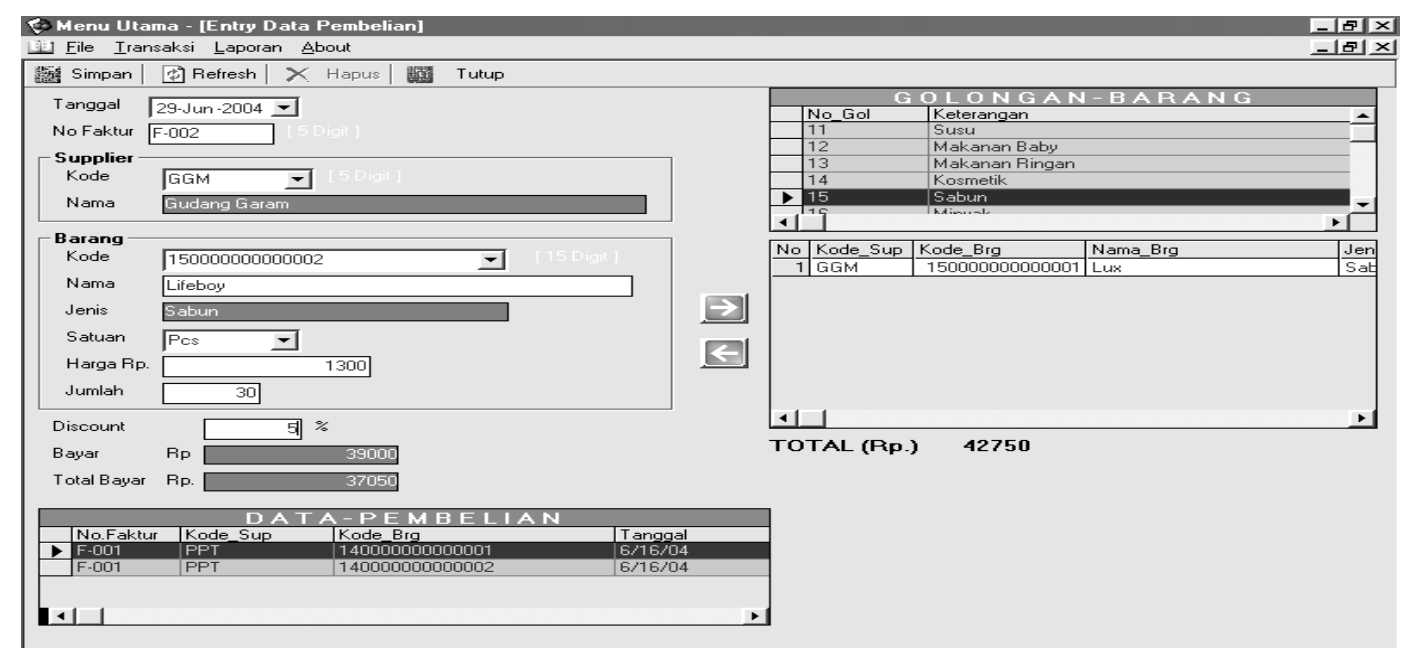

Gambar 18. Tampilan Entry Data Transaksi

Tampilan Entry Data Transaksi Penjualan dapat dilihat pada gambar 19 berikut:

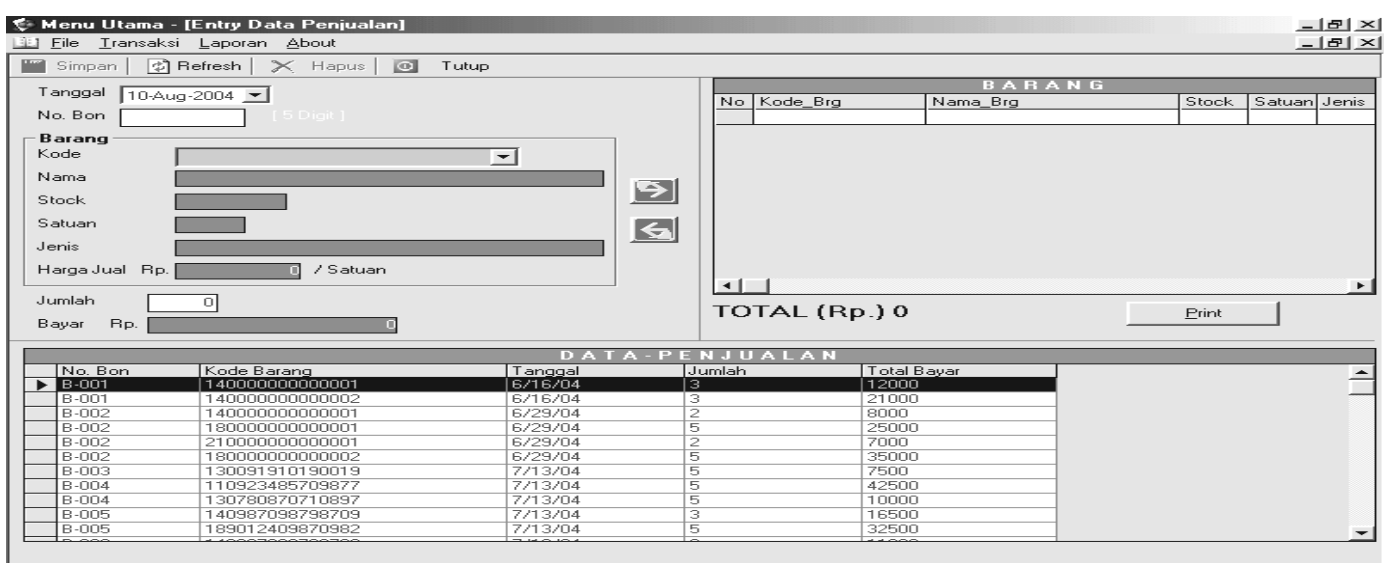

Gambar 19. Tampilan Entry Data Penjualan 


\subsection{Laporan}

Tampilan Laporan Persediaan Barang dapat dilihat pada gambar 20 berikut:

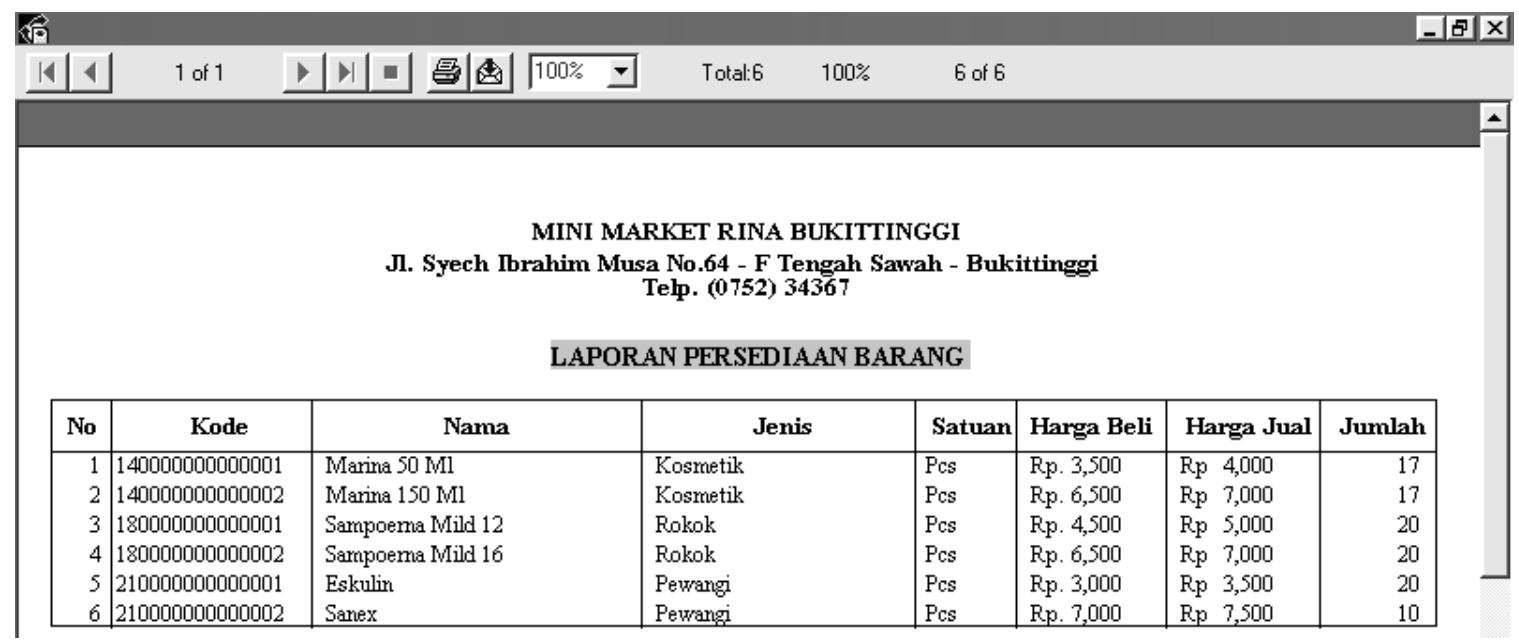

Gambar 20. Tampilan Laporan Persediaan Barang

Tampilan Laporan penjualan/bulan dapat dilihat pada gambar 21 berikut:

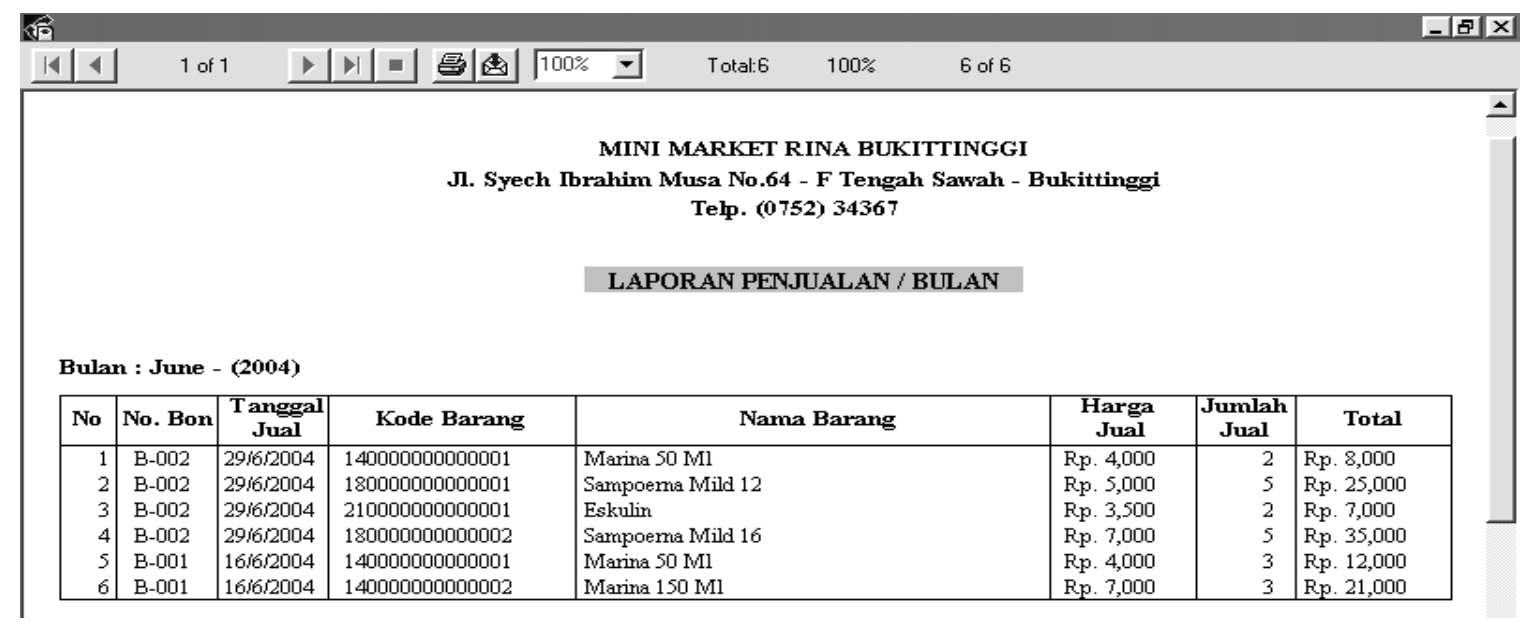

Gambar 21.Tampilan Laporan Penjualan/Bulan

Tampilan Laporan pembelian/bulan dapat dilihat pada gambar 22 berikut:

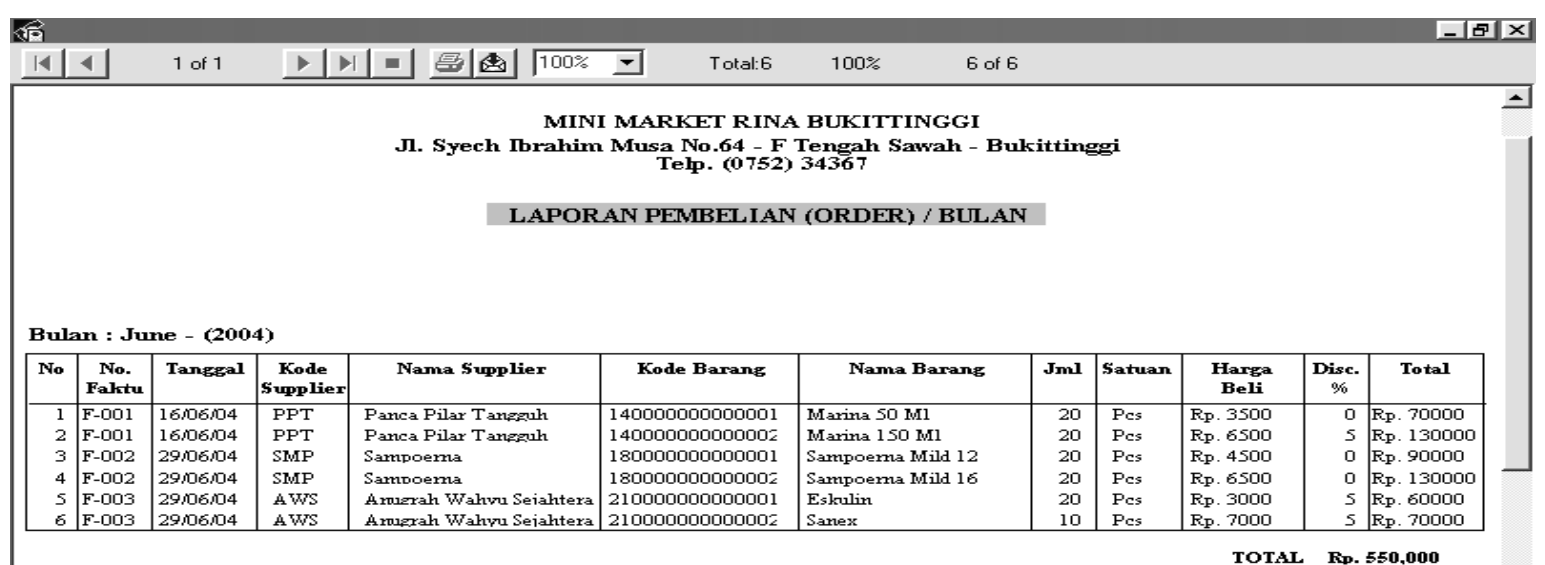

Gambar 22. Tampilan Laporan Pembelian/Bulan 


\section{PENUTUP}

Dengan rancangan sistem yang baru, pembuatan laporan-laporan yang berhubungan dengan informasi persediaan dapat dibuat secara cepat, tepat dan dapat meminimalkan kesalahan-kesalahan. Tujuan dari sistem ini dirancang adalah untuk dapat membantu mempercepat proses pembuatan laporan/informasi sesuai dengan yang diinginkan.

\section{DAFTAR PUSTAKA}

Nugroho, Eko, “Bahasa-bahasa Pemrograman”, Andi Offset, Yogyakarta, 2001.

Jogianto, H.M, “Analisa dan Disain Sistem Informasi”, Penerbit Andi Offset, Yogyakarta, 1999.

Kristanto, Andri, "Perancangan Sistem Informasi dan Aplikasinya", Penerbit Gaya Media, Yogyakarta, 2003.

Pamungkas, Ir, “Tip \& Trik Microsoft Visual Basic 6.0”, Penerbit PT. Elexmedia Computindo, Jakarta, 2001.

Pramono, Joko, “Mudah Menguasai Visual Basic 6.0”, PT.Elex Media Komputindo, Jakarta, 1999.

Rangkuti, Freddy, "Manajemen Persediaan", Penerbit PT. Raja Grafindo Persada, Jakarta, 2002.

Softjan, Assauri, "Manajemen Produksi Dan Operasi”, Lembaga Penerbit Fakultas Ekonomi Universitas Indonesia, Jakarta, 1998.

Suryo Kusumo, Ario, “Buku Latihan Microsoft Visual Basic 6.0”, PT.Elex Media Komputindo, Jakarta, 2000.

Suryo Kusumo, Ario, “Microsoft Visual Basic 6.0”, Penerbit PT. Elexmedia Computindo, Jakarta, 2002. 